\title{
IoT Based Sound and Air Pollution Measuring Temperature and Humidity Monitoring System
}

\author{
P. V. Hari Prasad ${ }^{1}$, Maddasani Daya Rani ${ }^{2}$, Garimella Keerthana ${ }^{3}$, Kollu Yaswanth Kumar ${ }^{4}$, and \\ Uppalapathi Bhargav ${ }^{5}$ \\ ${ }^{1}$ Associate Professor, Department of Computer Science \& Engineering, Dhanekula Institute of Engineering \& Technology, \\ Ganguru, India \\ ${ }^{2,3,4,5}$ Students, Department of Computer Science \& Engineering, Dhanekula Institute of Engineering \& Technology, \\ Ganguru, India
}

Correspondence should be addressed to P. V. Hari Prasad; maddasanidayarani904@gmail.com

Copyright () 2021 Made P. V. Hari Prasad et al. This is an open access article distributed under the Creative Commons Attribution License, which permits unrestricted use, distribution, and reproduction in any medium, provided the original work is properly cited.

\begin{abstract}
Now a day in metropolitan cities air and sound pollution becomes serious issues, because of high decibels and toxic gases present within the environment which directly effect on human health and thus needs a special attention. Therefore, it's now become necessary to regulate the pollution (air and noise) to ensure healthy livelihood and better future. In this paper, an efficient implementation for Internet of Things is employed for monitoring atmospheric conditions of environment like air pollution and noise pollution. And also we monitor The Temperature and Humidity. Using MQ7 sensor for sensing Carbon Monoxide (CO) and MQ135 gas Sensor for detecting wide range of gases, including $\mathrm{NH} 3$, NOx, alcohol, benzene, smoke and $\mathrm{CO} 2$.constantly transmit this data. Also, system keeps measuring sound level using MIC sensor and reports it. DHT11 sensor consists of a capacitive Humidity sensing element and Thermistor for sensing Temperature. Soil moisture is the amount of water in the soil. Soil moisture monitoring system that helps the govt authorities to understand the data about dry soil areas within the agricultural lands within a village, town or maybe a state so that the required precautionary steps will be taken to create such lands fertile.
\end{abstract}

KEYWORDS- MQ7 sensor, MIC sensor, DHT11 sensor, MQ135 gas Sensor.

\section{INTRODUCTION}

Nowadays, in Metropolitan cities air and noise pollution have become a serious issue, due to high decibels and toxic gases present in the environment which directly affect human health and thus needs special attention. Therefore, it has now become necessary to control pollution (air and noise), Temperature, and humidity to ensure healthy livelihood and a better future. In this paper, an effective implementation for the Internet of Things is used for monitoring atmospheric conditions of the environment like air pollution and sound pollution [3]. And also we Monitor the Soil moisture monitoring system that helps the government authorities to know the information about dry soil areas in the agricultural lands within a village, town, or maybe a state in order that the required precautionary steps will be taken to create such lands fertile.

Currently, Air contains harmful gases, such as $\mathrm{CO}$, Smoke, LPG, which cause harm to the environment and human health such as asthma [6][7], detecting these gases using MQ135, MQ7 sensor. Soil contains different moisture levels which may harm crops we need to determine the moisture level that is suitable for agriculture detecting with Soil moisture sensor Various kinds of environmental pollution cause major problems to mankind. Temperature and humidity sensor control the evaporation releases from the industry. Sound sensor detects the high levels of sound plays an important role in Traffic. Air contains harmful gases which harm human health. The above problems motivated us to implement this project [5].

\section{LITERATURE SURVEY}

Nagarajapandian $\mathrm{M}$ et al. have proposed the Automatic irrigation system on sensing soil moisture content. The continuously increasing demand for food requires the rapid improvement in food production technology. In a country like India, where the economy is especially supported agriculture and therefore the weather conditions are isotropic, still, we don't seem to be ready to fill use of agricultural resources. The main reason to use this is lack of rains \& scarcity of land reservoir water. The continuous extraction of water from the earth is reducing the underground water level due to which a lot of lands are coming slowly into the zones of un-irrigated land. Another important reason for this was the unplanned use of water because a major amount of water goes to waste [2].

Poonam Pal et al have proposed the IOT Based Air Pollution Monitoring System Using Arduino. The level of pollution has increased with times by a lot of factors like the increase in population, increased vehicle use, industrialization, and urbanization which results in harmful effects on a human being by directly affecting the health of population exposed to it when there are more amount of harmful gases are present within the air like CO2, smoke, alcohol, benzene, and NH3. It will show the air quality in PPM on the LCD and the web page so we are ready to monitor it very easily. In this IoT project, you'll be able to 
monitor the pollution level from anywhere using your computer or mobile. The main objective of the Air \& Sound Monitoring System is that to monitor the air and sound pollution is a growing issue these days, It is necessary to observe air quality and keep it in check for a much better future and healthy living for all. Due to flexibility and low cost of processing Internet of things (IoT) is getting popular day by day[4].

L. Rama Devi et al. have proposed the Remote Soil Moisture Monitor Using IoT, Soil moisture sensors measure the volumetric water content in the soil. Since the direct gravity measurement of free soil moisture requires removing, drying, and weighting the sample, soil moisture sensors measure the volumetric water content indirectly by using another property of the soil, like resistance, dielectric constant, or interaction with neutrons, as a proxy for the moisture content[1]. Soil moisture sensors measure the volumetric water content in the soil which gives us the moisture of the soil.

\section{PROPOSED SYSTEM}

Proposing the combination of air, sound pollution, temperature and humidity, soil monitoring and notification systems and making into a single system using IoT. Detection of harmful gases such as CO, Smoke, LPG etc. By using MQ7MQ135 gas sensors, detection of soil moisture level using soil sensor. Implementation of temperature and humidity sensor. Detection of noise level using sound sensor. Usage of Arduino to get the parameters values as a message to the mobile phone when it crossed some limit and continuous monitoring of the parameters values using app and if it crossed some amount of limit some authority people will the notification message.

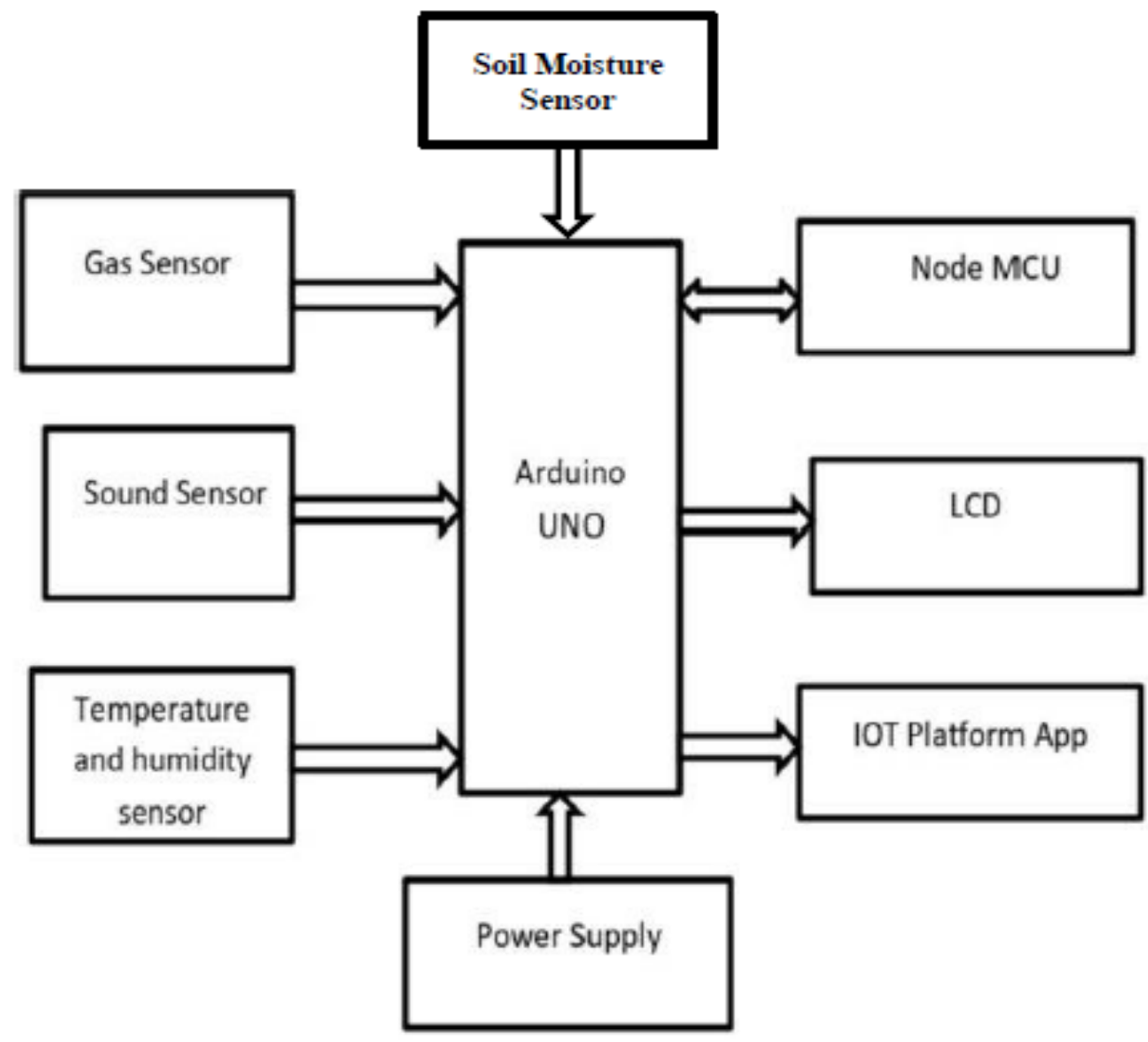

Fig. 1: Block Diagram.

In this proposed system, we are connecting the gas sensor to the Arduino UNO which helps us to detect the harm full gases in the air, and soil moisture is also connected to the to Arduino UNO which helps to identify the moisture in the soil and sound sensor is also connected to Arduino UNO which helps to detect sound these all values of sensor is shown in the mobile app which is developed by using IoT Platform app that is Blink app and the values also uploaded in website also as shown in the Figure 1.

\section{Advantages of Proposed System:}

- We can easily find the dangerous gases present around us.

- We can also know the humidity and moisture in soil by using app. 


\section{IV.SYSTEM DESIGN}

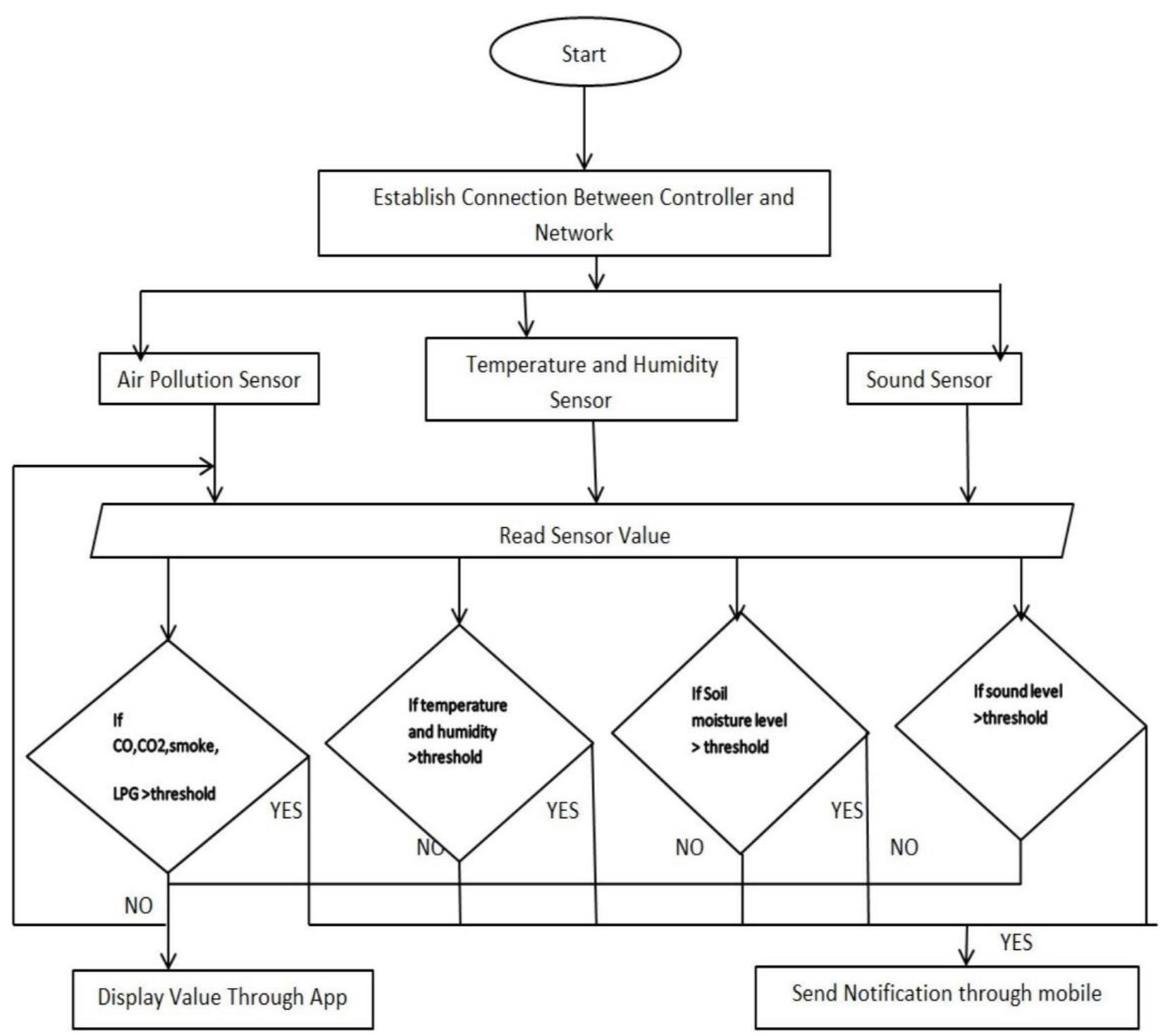

Fig. 2: Flow Chart.

The Figure 2 tells us the complete flow of detecting the sound, air pollution, also the humidity in the atmosphere, temperature (room temperature), and moisture in the soil.

Steps:

- We had created an Android App to measure the humidity and the moisture in the temperature called blink

- The person need to login into the app and should be register with a mobile number.

- Once the connection is established between the all sensors like air pollution sensor temperature and humidity sensor sound sensor with network.

- Then all sensor read their values and these values are mapped with threshold values of each and every sensor.

- If the values are less than threshold values then this process will continue repeatedly.

- If the values are greater than threshold values then the alert message is send to the registered mobile number.
V. RESULTS

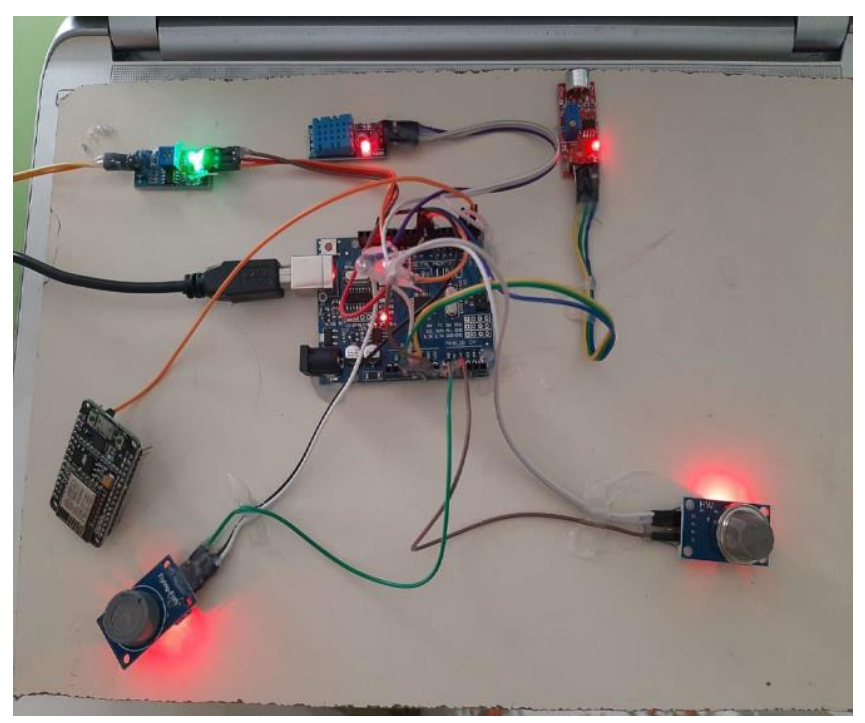

Fig. 3: Prototype 
The output of this pollution monitoring as shown in Figure 3. We measure several gases and high-intensity noise that can lead to degradation of the atmosphere. Noise Intensity and Gases like Carbon Monoxide, Smoke, Cooking Fumes and Carbon Dioxide are Monitored in Real-Time Using this System. Real-Time Monitoring enables us to take timely action using IoT to prevent any major mishaps. The indication will be given through the device if the air and noise pollution increase from the given threshold value (decided by the programmer). Each IoT device is identified by the channel Id allocated to it. This application can be used to get knowledge regarding pollution the air and sound pollution monitoring system shows the digital value of air and sound pollution. The air \& sound monitoring system overcomes the problem of the highly polluted areas which is a major issue to be solved.

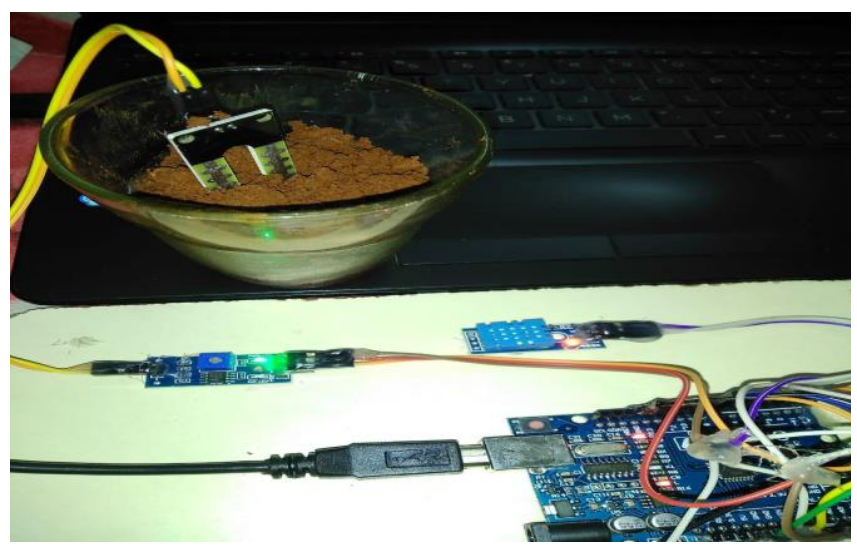

Fig. 4: Measuring the moisture of soil.

The above Figure 4 shows a low-cost wireless sensor network system for soil moisture monitoring. The flexibility of the sensor and transceiver node to integrate with another type of sensor was tested and implemented in this work. The characteristic proved that the accuracy of the sensor in determining the moisture content present in the soil. It also showed that volumetric water content can be used to monitor and schedule irrigation in agricultural lands. Monitoring of PH \& Temperature of Water makes use of water detection sensors with a unique advantage and existing GSM network.

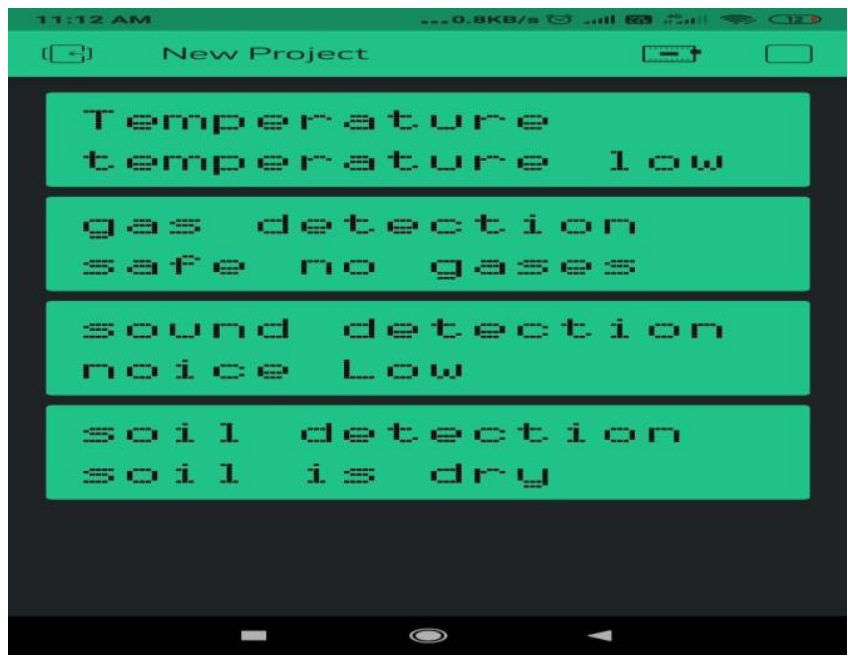

Fig. 5: Shows Temperature.
The above Figure 5 shows the temperature and humidity is low that indicates that we are in the room temperature.

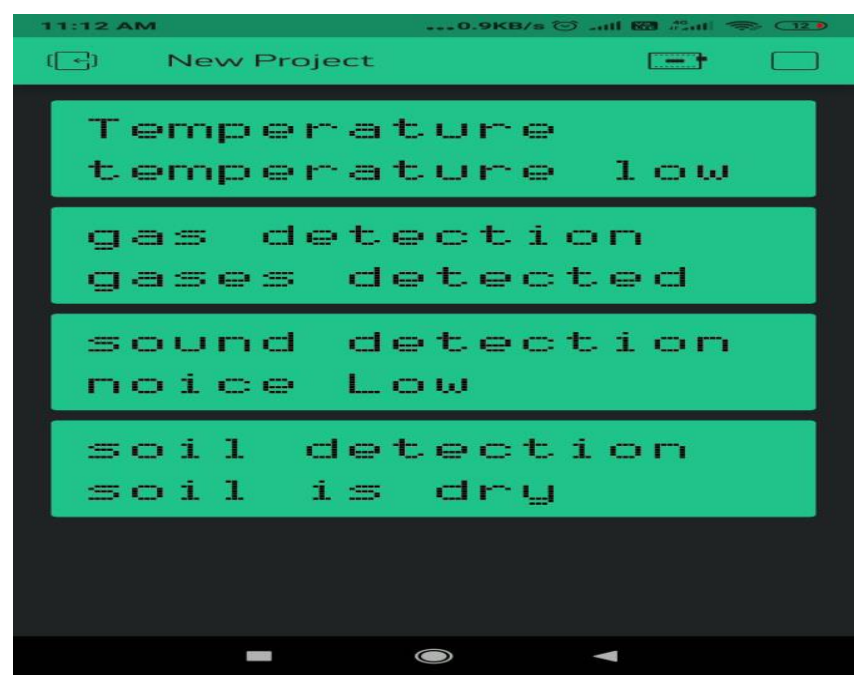

Fig. 6: shows gas levels in air.

The above Figure 6 shows that the gases are detected by the gas detection sensor in the room.

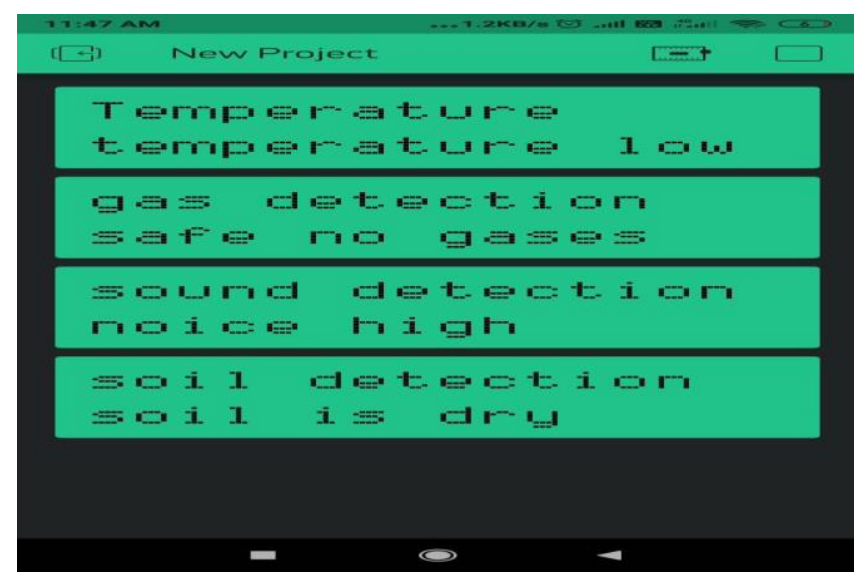

Fig. 7: Detects sound.

The above Figure 7 shows that the noise is high level of noise using MIC Sensor.

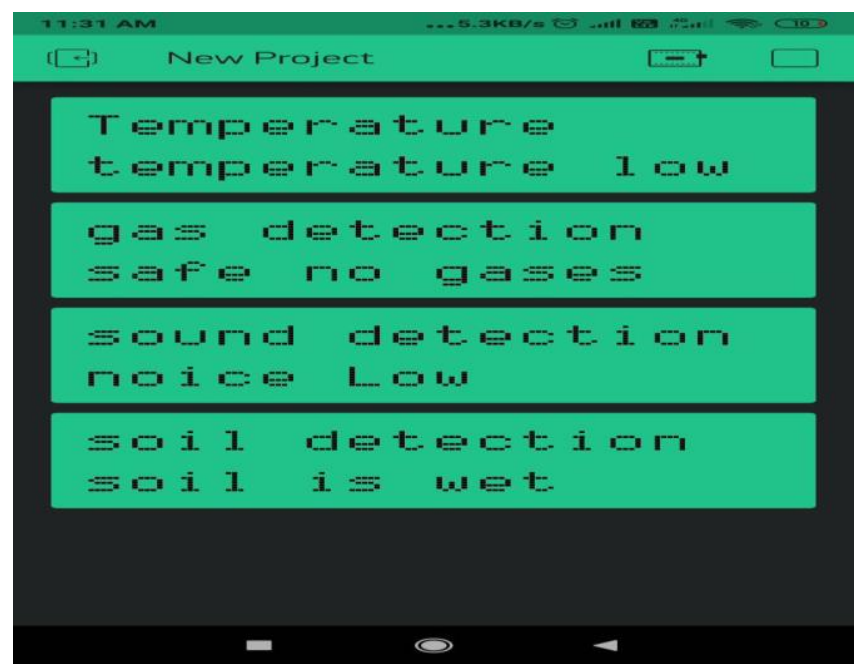

Fig. 8: Detects the moisture in the soil. 
The above Figure 8 shows that the soil is wet when the soil moisture is dipped into the fertile soil.

\section{CONFLICTS OF INTEREST}

The authors declare that they have no conflicts of interest.

\section{CONCLUSION}

The system to observe various parameters of environment using Arduino microcontroller, WSN and GSM Technology is proposed to enhance quality of air. With the utilization of technologies like WSN and GSM enhances the method of monitoring various aspects of environment like air quality monitoring issue proposed during this paper. so that the required action could also be taken. It is estimated that this technique will have an excellent acceptance within the market because it may be a centralized system for an entire monitoring function. The smart thanks to monitor the environment and an efficient, low cost embedded system is presented with different models during this paper. In the proposed architecture function of various modules were discussed. The noise and air pollution monitoring system with Internet of Things concept experimentally tested for monitoring two parameters. This model are often further expanded to watch the developing cities and industrial zones for pollution monitoring. To guard the general public health from pollution, this model provides an efficient and low cost solution for continuous monitoring of environment and soil moisture monitoring. The flexibility of the sensor node and transceiver node to integrate to other sort of sensor was tested and implemented on this work. The characteristic curve proved the accuracy of the sensor in determining the soil moisture content. Monitoring of Turbidity, PH \& Temperature of Water makes use of water detection sensor with unique advantage and existing GSM network.

\section{REFERENCES}

[1] Dhruvil Shah, PrathmeshKudale, Prasad Shirwadkar, Samuel Jacob, Iot Based Air and Sound Pollution Supervising System, IOSR Journal of Engineering, 2018.

[2] Arushi Singh, Divya Pathak, Prachi Pandit, Shruti Patil, Prof. Priti . C. Golar, IOT based Air and Sound Pollution Monitoring System, International Journal of Advanced Research in Electrical, Electronics and Instrumentation Engineering, 2017.

[3] Sindhu .K .G, Shruthi. H, Sumanth. M. B, Vijayashree. H. M, Ayesha. A. P, IOT Based Air and Noise Pollution Monitoring System, International Journal of Innovative Research in Science, Engineering and Technology, 2018

[4] Ms. SarikaDeshmukh, Mr . SaurabhSurendran, Prof. M.P. Sardey, Air and Sound Pollution Monitoring System using IoT, Intern ational Journal on Recent and Innovation Trends in Computing and Communication, 2017.

[5] P. Sai Chandana, K. Sreelekha, A. Muni Likith Reddy, M. Anil Kumar Reddy, R. Senthamilselvan, IOT Air And Sound Pollution Monitoring System, International Journal on Applications in Engineering and Technology, 2017.
[6] Anushka Sharma, Vaishnavi Varshney, Roopank Maheshwari, Upasana Pandey, IOT Based Air And Sound Pollution Monitoring System, International Research Journal of Engineering and Technology, 2018.

[7] Lalit Mohan Joshi, Research paper on IOT based Air and Sound Pollution Monitoring System, International Journal of Computer Applications, 2017.

\section{ABOUT THE AUTHORS}

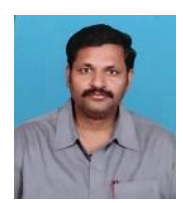

P. V. Hari Prasad. Associate Professor in Department of Computer Science \& Engineering, Dhanekula Institute of Engineering and Technology, Ganguru

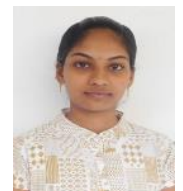

Maddasani Daya Rani, Student in Department of Computer Science \& Engineering, Dhanekula Institute of Engineering and Technology, Ganguru

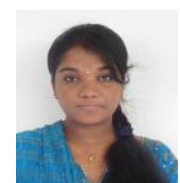

Garimella Keerthana, Student Department of Computer Science \& Engineering, Dhanekula Institute of Engineering and Technology, Ganguru

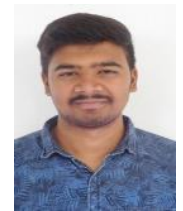

Kollu Yaswanth Kumar, Student in Department of Computer Science \& Engineering, Dhanekula Institute of Engineering and Technology, Ganguru

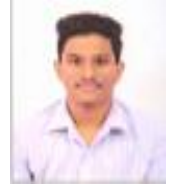

Uppalapathi Bhargav, Student, in Department of Computer Science \& Engineering, Dhanekula Institute of Engineering and Technology, Ganguru 